\title{
Author Correction: A multi-country meta-analysis on the role of behavioural change in reducing energy consumption and $\mathrm{CO}_{2}$ emissions in residential buildings
}

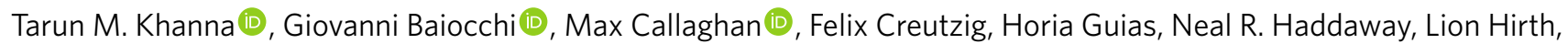
Aneeque Javaid (D), Nicolas Koch D, Sonja Laukemper, Andreas Löschel (D, Maria Del Mar Zamora and Jan C. Minx (D)

Correction to: Nature Energy https://doi.org/10.1038/s41560-021-00866-x, published online 26 July 2021.

In the version of this article initially published, a grant number in the Acknowledgements was truncated. It has now been to amended to read "Funding by the German Ministry for Education and Research ... Ariadne (ref. no. 03SFK5J0, J.C.M.) project[s] is gratefully acknowledged."

The change has been made to the online version of the article.

Published online: 29 November 2021

https://doi.org/10.1038/s41560-021-00961-z

(c) The Author(s), under exclusive licence to Springer Nature Limited 2022 